\section{Porta hepatis schwannoma diagnosed by endo- scopic ultrasound-guided fine-needle biopsy}
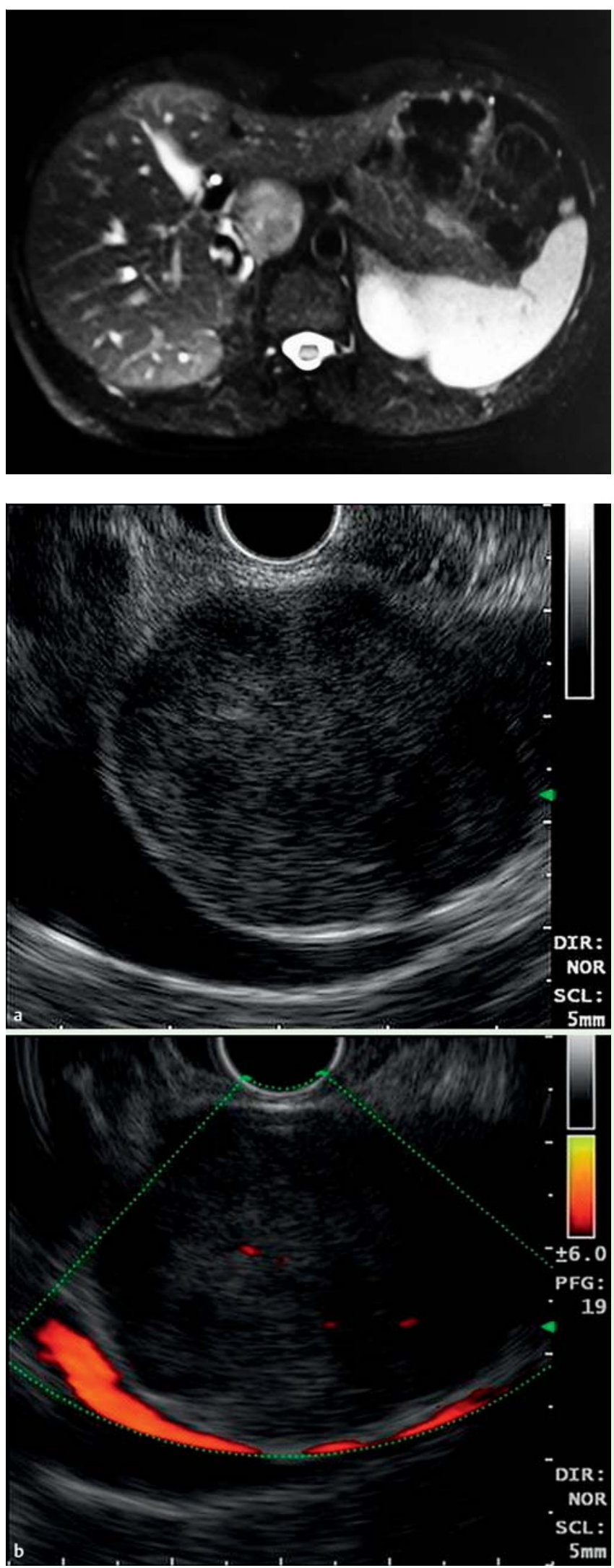

Fig. 1 A 30-year-old woman presented with an isolated episode of moderate abdominal pain in the upper-right quadrant. An abdominal T2-weighted MRI scan revealed a heterogeneous low-attenuation tumor in the porta hepatis measuring $4 \mathrm{~cm}$ in size that was compressing the portal vein and touching the common bile duct.

Fig. 2 Linear-array endosonography shows: a a $3.8 \times 3.4-\mathrm{cm}$ well-circumscribed and hypoechoic mass compressing the portal vein; b small Doppler signals.
A 30-year-old white woman was referred 5 months ago for evaluation of an isolated episode of moderate abdominal pain in the upper-right quadrant. An abdominal computed tomography scan revealed a heterogeneous low-attenuation tumor, measuring $4 \mathrm{~cm}$ in size in the porta hepatis, which was compressing the portal vein and touching the common bile duct ( $\bullet$ Fig. 1 ).

Sectorial endoscopic ultrasound (Olympus GF-UCT180 coupled to an ultrasound unit Olympus EU-ME1; Olympus America Inc., New York, USA) detected a well-circumscribed and hypoechoic mass with small Doppler signals in the porta hepatis, which measured $3.8 \times 3.4 \mathrm{~cm}$ and was located between the portal vein and the left lobe of the liver ( $\bullet$ Fig. 2 a,b). Endoscopic ultrasound-guided fine-needle biopsy (EUS-FNB) was performed using a 19-gauge needle (EchoTip Ultra Echo-19; Cook Medical, Winston-Salem, USA) for four passes. A spindle cell tumor that was strongly immunoreactive for S-100 was found, defining the mass as a schwannoma ( Fig.3a,b). Once detected by full laparotomy ( $\bullet$ Fig.4), the tumor was successfully removed ( $\bullet$ Fig. $\mathbf{5}$ a,b) and the patient was completely asymptomatic 3 months after the surgery.

A schwannoma is a tumor that arises from neural crest-derived Schwann cells in the sheath of peripheral nerves [1]. The involvement of the porta hepatis by schwannomas is very rare, and only four cases have been reported in the literature, which were all confirmed only after surgical resection [2-5]. Ours is the first patient to be diagnosed before surgery by means of EUS-FNB of the lesion and a positive reaction for S-100 in the cell block. The lesion is clinically asymptomatic in most cases until it reaches a large size and causes symptoms associated with compression. Diagnosis of this tumor is difficult due to its rarity, lack of symptoms until late in the clinical course, and the lack of specific diagnostic blood tests or features identifiable in imaging studies. Tumor size is related to the malignant potential. Surgery is the treatment of choice and is usually curative [1].

EUS findings generally reveal a well-circumscribed hypoechoic mass. EUS-FNB of porta hepatis tumors is a valuable method for the preoperative diagnosis of schwannomas.

Endoscopy_UCTN_Code_CCL_1AF_2AZ_3AD

Competing interests: None 

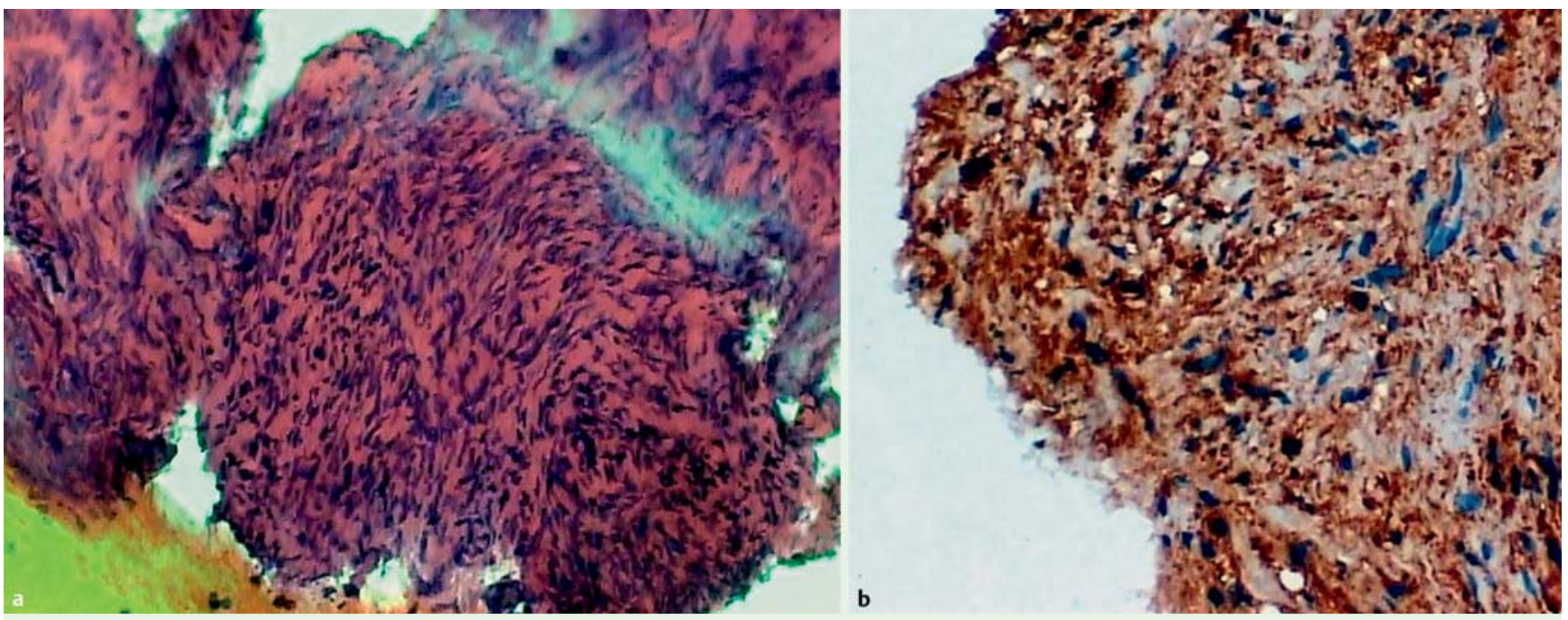

Fig. 3 Histopathological findings from the schwannoma found in the porta hepatis. a A cellular specimen shows large, cohesive groups of spindle cells with nuclear palisading (cell block, hematoxylin and eosin; original magnification $\times 40$ ). b An immunohistochemical stain for S-100 shows diffuse nuclear and cytoplasmic staining (polyclonal S-100, original magnification $\times 400$ ).

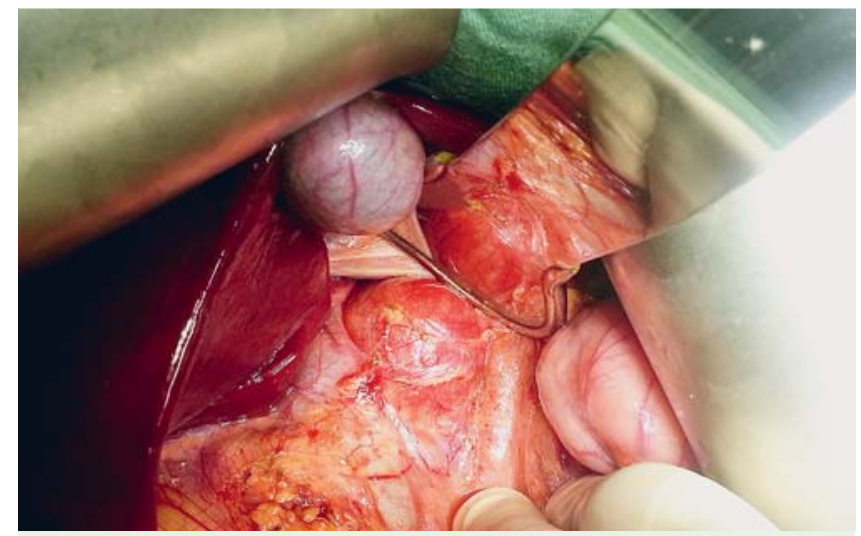

Fig.4 A full laparotomy revealed the tumor behind the portal vein.

César V. Lopes ${ }^{1}$, Uirá F. Teixeira²,

Fábio L. Waechter², José A. Sampaio², Antônio A. Hartmann ${ }^{3}$

${ }^{1}$ Department of Gastroenterology and Digestive Endoscopy, Santa Casa Hospital, Porto Alegre, Brazil

2 Department of Gastrointestinal Surgery, Santa Casa Hospital/Federal University of Health Sciences of Porto Alegre (UFCSPA), Porto Alegre, Brazil 3 Department of Pathology, Santa Casa Hospital, Porto Alegre, Brazil

\section{References}

1 Li Q Gao C, Juzi JT et al. Analysis of 82 cases of retroperitoneal Schwannoma. ANZ J Surg 2007; 77: 237-240

2 Panait L, Learn P, Dimaio C et al. Resection of perihilar biliary schwannoma. Surg Oncol 2011; 20: 157-159

3 Kulkarni N, Andrews SJ, Rao V et al. Case report: Benign porta hepatic schwannoma. Indian J Radiol Imaging 2009; 19: $213-215$

4 Park MK, Lee KT, Choi YS et al. A case of benign schwannoma in the porta hepatis. Korean J Gastroenterol 2006; 47: 164-167

\section{Bibliography}
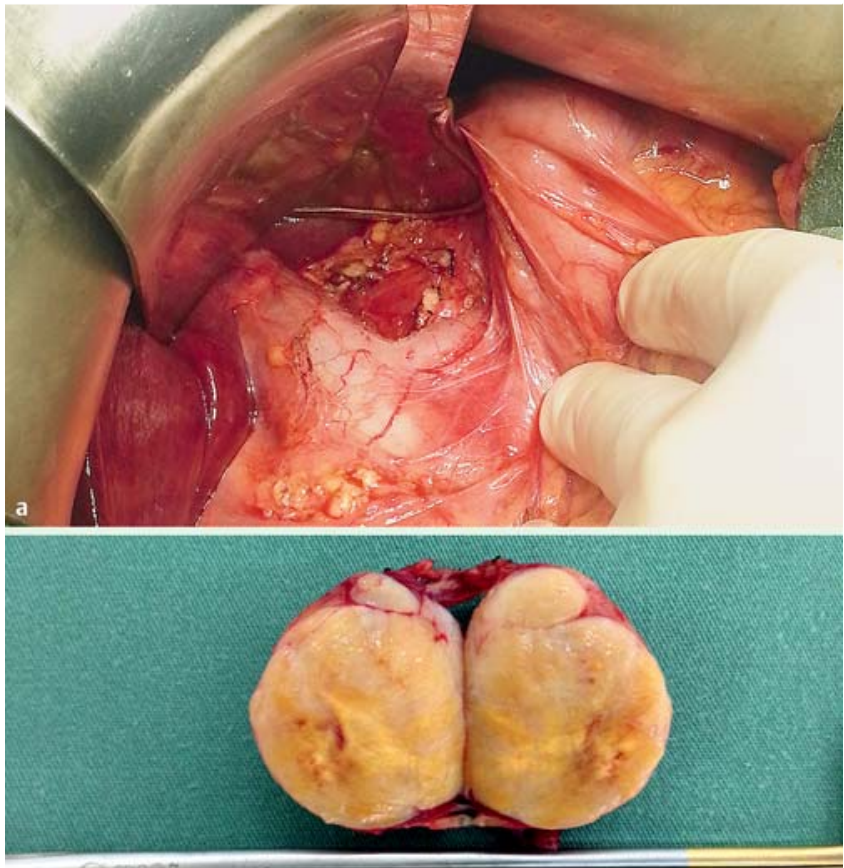

b

Fig.5 a Portal vein completely free after resection of the tumor. b Macroscopic appearance of the cut surface of the resected tumor showing a 4-cm, yellow, firm, and encapsulated solid tumor.
5 Choi $H$, Whitman G, Ro J et al. Benign schwannoma in the porta hepatis. AJR Am J Roentgenol 2001; 177: 652

DOI http://dx.doi.org/

10.1055/s-0034-1392213

Endoscopy 2015; 47: E257-E258

(c) Georg Thieme Verlag KG

Stuttgart · New York

ISSN 0013-726X
Corresponding author

César V. Lopes, MD

Rua Prof. Cristiano Fischer 668/1001

C.E.P. $91.410-000$

Porto Alegre-RS

Brazil

Fax: +55-51-33388054

drcvlopes@gmail.com 